\title{
Prognosis of patients treated in a single neurosurgical reference centre for brain metastasis caused by dormant disseminated cells
}

\author{
LORENZO FERLINI ${ }^{1}$, LORENZO PELUSO ${ }^{2}$, VALENTINA LOLLI $^{3}$, \\ NICOLAS GASPARD ${ }^{1}$ and FLORENCE LEFRANC ${ }^{4}$ \\ Departments of ${ }^{1}$ Neurology, ${ }^{2}$ Intensive Care, ${ }^{3}$ Radiology and ${ }^{4}$ Neurosurgery, Erasmus Hospital, \\ Free University of Bruxelles, B-1070 Brussels, Belgium
}

Received August 5, 2020; Accepted December 30, 2020

DOI: $10.3892 / \mathrm{ol} .2021 .12715$

\begin{abstract}
Brain metastasis (BM) is a frequent complication of systemic cancer usually associated with poor prognosis. Survival depends on numerous factors, which complicates prognosis and treatment. It has been suggested that BM growing from previously dormant disseminated tumour cells (DTCs) may exhibit a milder phenotype than BM derived from continuously progressing metastatic cells; however, to the best of our knowledge, the prognosis of patients presenting with BM from dormant DTCs is unknown. The present study retrospectively compared survival data, collected from a single neurosurgical centre, between patients presenting with BM from previously dormant DTCs and patients with non-dormant BM. A total of 262 medical records were reviewed. In the univariate Cox regression analysis, the median survival of the dormant BM group was statistically longer than that of the non-dormant group $(\mathrm{P}=0.048)$; a trend towards a longer survival persisted after correcting for age, presence of breast cancer and treatment options $(\mathrm{P}=0.057)$, which are all factors known to influence outcome. The improved outcome of these patients could be considered in models for prognostication. Moreover, the development of therapies able to eradicate dormant DTCs could provide a new promising strategy to prolong the survival of patients with a favourable prognosis.
\end{abstract}

\section{Introduction}

Brain metastasis (BM) is a frequent complication of systemic cancer types (1). Although highly dependent on the primary tumour (PT) and histological subtype (2), the prognosis of BM is often poor (3). Epidemiological studies have shown a BM incidence of $10-30 \%$ (4-6); however, due

Correspondence to: Dr Lorenzo Ferlini, Department of Neurology, Erasmus Hospital, Free University of Bruxelles, 808 Route de Lennik, B-1070 Brussels, Belgium

E-mail: lorenzo.ferlini@erasme.ulb.ac.be

Key words: brain metastasis, dormancy, prognosis, disseminated tumour cells, solid cancer to improvements in the systemic treatment of PTs, leading to a longer survival, and the detection capabilities of imaging modalities, this incidence is expected to increase (3). Recent evidence has suggested that dissemination might occur during the early stage of tumour evolution (7-9), even before the manifestation of the PT (10). Depending on the PT site (3), the delay between PT diagnosis and BM presentation can range from a few months to several years. In fact, early undetectable disseminated tumour cells (DTCs) might become refractory to conventional therapies after extravasation and seeding in a target organ, since they enter dormancy (Fig. 1) (11-13). For that reason, DTCs can be the source of late tumour recurrence.

Solitary tumour cell dormancy is defined as a reversible non-proliferative cellular state characterized by temporary mitotic and growth arrest (13), probably as the consequence of a delayed adaptation to the microenvironment of the pre-metastatic site (14). Further genetic and epigenetic mutations allow dormant cells to overcome target organ inhibitory signals, undergo mesenchymal-to-epithelial transformation and stimulate neoangiogenesis, a required step for proliferation (15-20). This process could result in the delayed occurrence of metastasis. Continuous tumour growth models have failed to explain the long interval between PT diagnosis and distant disease recurrence, and indeed, the clinical data point to a dormancy-based model for this delayed metastatic development $(21,22)$. To the best of our knowledge, no previous study has analysed whether a selected population of patients presenting with BM growing from dormant DTCs (i.e., patients with a long progression-free interval between PT and BM diagnosis with neither PT recurrence nor other metastatic localizations) have a prolonged survival. DTCs have been shown to have a less aggressive phenotype than that of PTs or overt metastases (23). Therefore, the present study aimed at determining whether dormant BM positively influences survival. We retrospectively collected data on patients presenting with a BM managed at our institution between January 2004 and December 2019 to provide descriptive statistical analyses of our cohort. We particularly focused on those patients presenting with a long progression-free interval before the BM diagnosis. The secondary aim was to analyse the clinical characteristics of PTs and BMs that are linked to the phenomenon of dormancy. 


\section{Materials and methods}

Patients. All patient medical records included in our institutional (Erasmus Hospital, Free University of Bruxelles, Belgium) neurosurgical database of BM between January 2004 and December 2019 were reviewed. In addition, cases of cerebral metastasis discussed in weekly multidisciplinary team meetings during the same period were included in the medical records review, following the exclusion of duplicates. The inclusion criterion for further analysis was $\geq 1$ histologically confirmed BM from a solid extracerebral PT. Patients with a high suspicion of BM but without a histological confirmation were, as a consequence, excluded. The other exclusion criteria were a lack of clinical data, vertebral or skull bone metastasis, leptomeningeal metastasis and other final diagnoses (i.e. inflammatory process or brain primary tumour). For each included case, the following information was collected from the medical records: Sex, age at PT diagnosis, histological and molecular PT type, work-up and follow-up assessment, age at BM diagnosis and time span between BM and PT diagnoses, BM localization and associated symptoms, presence of previous or simultaneous distant localizations at BM diagnosis, treatment of the BM and follow-up. Based on this information, patients were classified into three groups. The first group included patients with BMs from an unknown PT (uPT group), the second included patients presenting with a $\mathrm{BM}$ from a known cancer with local or systemic progression, or both (pPT group), and the last group included patients experiencing a progression-free period following PT treatment without local or distant recurrence at the moment of BM diagnosis (dPT group). To exclude undetectable but already growing $\mathrm{BM}$ at the time of the $\mathrm{PT}$ diagnosis, only patients presenting with a minimum of 30 months of progression-free disease were included in the dPT group (24). Only PT origins found in $>2 \%$ of the total cohort were considered independently; less frequently observed PT origins were placed in the 'other' group. Since drugs targeting specific molecular tumour profiles have a positive influence on outcome (25), the molecular biology phenotype was included in the survival analysis. Since receptor expression in breast cancer allowed for specific treatments (26), immunohistochemistry was included in the molecular biology group.

Statistical analysis. Statistical analysis was performed using IBM SPSS $^{\circledR}$ for Windows version 25 (IBM Corp). $\mathrm{P}<0.05$ was considered to indicate a statistically significant difference. Categorical variables are expressed as a count (percentage), whereas continuous data are presented as a median and interquartile range (IQR). Kruskal-Wallis, Fisher's exact and $\chi^{2}$ tests were used to analyse differences in variables between groups, as appropriate. The Dunn's post hoc test was employed in case of $\mathrm{P}<0.05$. The Kaplan-Meier method, the log-rank test and Cox regression were used for survival analysis. Variables with a $\mathrm{P}<0.1$ in the univariate analysis were included in the multivariate Cox model. Furthermore, if the absolute value of the estimated correlation between two variables was $\geq 0.3$, one of the variables was excluded from the multivariate analysis. A backward stepwise method was used with variables entering the model if their probability value was $\leq 5 \%$, and leaving the model if the value was $>10 \%$. All reported probabilities were two-sided.

\section{Results}

Included patients. After obtaining approval from the ethics committee (approval no. P2019/319), the medical records of 346 patients admitted to our institution (Erasmus Hospital, Free University of Bruxelles, Belgium) for suspected BM between January 2004 and December 2019 were reviewed. A total of 85 patients were excluded from further analysis for the following reasons: 19 patients did not have histological confirmation of the metastatic origin of the brain lesion; information was missing for 12 patients; 49 patients underwent neurosurgery for vertebral or skull bone metastasis and not for parenchymal lesions; and for five patients, the final histological diagnosis did not confirm the initial BM hypothesis. Thus, 261 patients were included in the analysis. Two illustrative case are reported herein.

Case 1. A 55-year-old woman was admitted to the neurology department for headache and progressive cognitive decline. The only significant previous medical issue, except for arterial hypertension, was a serous papillary carcinoma of the left ovary (T3cNOM0, positive for oestrogen receptors) treated by chemotherapy (carboplatin and Taxotere) and hysterectomy with salpingo-oophorectomy 4 years earlier; a standard follow-up assessment showed neither local nor distant cancer recurrence. Bradypsychia without lateralization signs was observed during the neurological examination. Magnetic resonance imaging (MRI) of the brain, performed during hospitalization (Fig. 2A-C), revealed a large ring-enhancing right frontal lesion with extensive oedema and subfalcine herniation. Neither local nor distant recurrences of the primary tumour were found after a complete work-up. Resection of the brain lesion was performed. The pathological analysis revealed oestrogen receptor-positive ovarian cancer metastasis. Brain radiotherapy (30 Gy in 10 fractions) was delivered after neurosurgery. The BM progressed 2 years later with the appearance of a second lesion in the right occipital lobe that was treated by radiotherapy (30 Gy in 5 fractions). Despite treatment, the cancer progressed; a decision for palliative care was subsequently assumed. The patient succumbed 45 months after the first BM diagnosis. This case is remarkable compared with what has been reported in the literature (27); the patient showed a considerably longer progression-free survival (40 vs. 24 months) and overall survival duration after BM diagnosis (45 vs. 6.4 months).

Case 2. An 82-year-old patient was admitted to the emergency department of our institution due to a 1-minute loss of consciousness. The patient complained of gait instability for several months before admission, and family members reported progressive cognitive decline, particularly in executive functions. The patient had a medical history of hypertension, hyperlipidaemia, type 2 diabetes, mild cognitive impairment, obstructive sleep apnoea, laminectomy for narrow lumbar spine canal syndrome and carotid endarterectomy for high-grade right carotid stenosis. A noteworthy consideration is that, 20 years earlier, he underwent local and inguinal lymph node dissection surgery and 1 year of interferon- $\alpha$ adjuvant therapy for cutaneous melanoma in the left leg (Breslow depth $1.15 \mathrm{~mm}$, Clark level 2, T2aN1aM0, Stage I); work-up and 

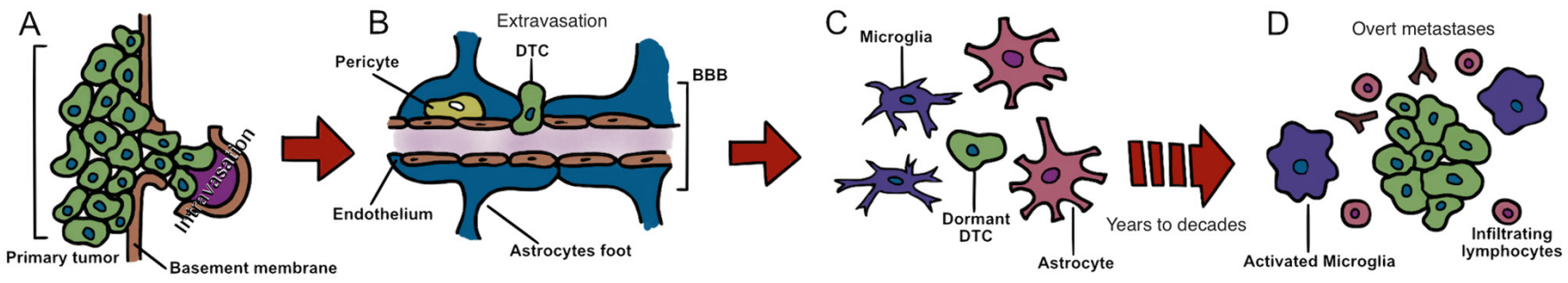

Figure 1. Cancer cell metastatic dissemination and dormancy. (A) Initially, tumour cells leave the primary tumour mass and invade vascular system (intravasation). (B) Next, DTCs successively spread and seed to the brain. Following adhesion, DTCs extravasate through the BBB and enter the brain. (C) DTCs activate self-imposed dormancy programs that allow them to adapt to the new microenvironment. (D) The accumulation of new genetic alterations allows DTCs to exit quiescence, activate the angiogenic switch and facilitate the evasion of the immune system leading to tumour cell expansion. It may take years for these steps to be completed. DTCs, disseminated tumour cells; BBB, blood-brain barrier.

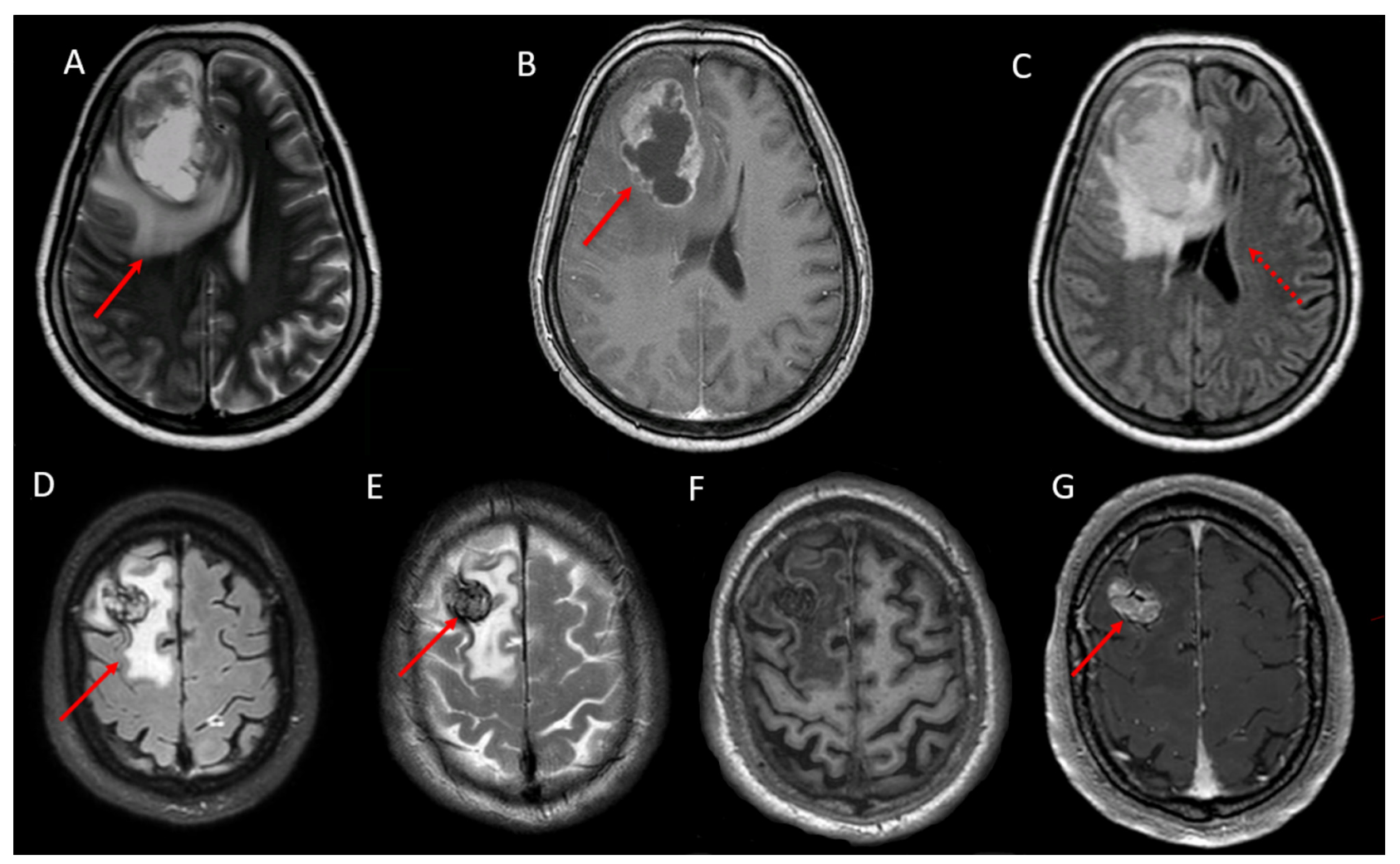

Figure 2. Case 1: (A) Axial T2-, (B) post-gadolinium T1- and (C) T2 FLAIR-weighted images showing a large intra-axial ring-enhancing right frontal lesion (arrows in B), with extensive surrounding oedema (arrow in A). A severe mass effect with a midline shift and subfalcine herniation was observed (dashed arrow in C). Case 2: (D) Axial T2 FLAIR-, (E) T2- and (F) pre- and (G) post-gadolinium T1-weighted-images showing a 25x5 mm heterogeneous mass lesion that developed in the right superior frontal sulcus (arrow in E). The lesion was hypointense on both T1- and T2-weighted images (arrow in E), likely due to haemorrhage, and was vividly enhanced following contrast injection (arrow in G). Surrounding vasogenic oedema was observed (arrow in D), but only with a mild effacement of the adjacent sulci. FLAIR, fluid attenuated inversion recovery.

follow-up screenings were negative for metastasis. MRI of the brain after admission revealed a $25 \times 5 \mathrm{~mm}$ right frontal lesion surrounded by vasogenic oedema (Fig. 2D-G); a second small left temporal lesion was also suspected. The LDH levels in blood samples were normal (178 U/l; normal range, 135-225 U/1). A course of dexamethasone was prescribed and the patient underwent neurosurgery for the larger lesion a few days later. Pathological and molecular analysis showed BRAF V600 E-mutated melanoma metastasis. A thorough assessment revealed neither local nor distant recurrences of the primary tumour. Gamma knife intervention was proposed for the second lesion, but the patient declined. He was thus transferred to a palliative care institution. Here, the case of a patient who experienced 20 years of disease-free survival before presenting a BM at a unique recurrence site of his primary tumour was presented; unfortunately, due to patient refusal, despite proposed treatment options, it was not possible to achieve long-term survival.

Patient characteristics. Patient characteristics are summarized in Table I. A slight female predominance was present in the current cohort $(\mathrm{n}=144 ; 55 \%)$. The PTs most commonly associated with BM were lung $(\mathrm{n}=138,53 \%)$, breast $(n=44 ; 17 \%)$, melanoma $(n=20 ; 8 \%)$ and colon-rectal cancer types $(n=15 ; 6 \%)$. In $37 \%$ of cases $(n=98)$, BM was the first manifestation of a previously unknown PT. A total of 


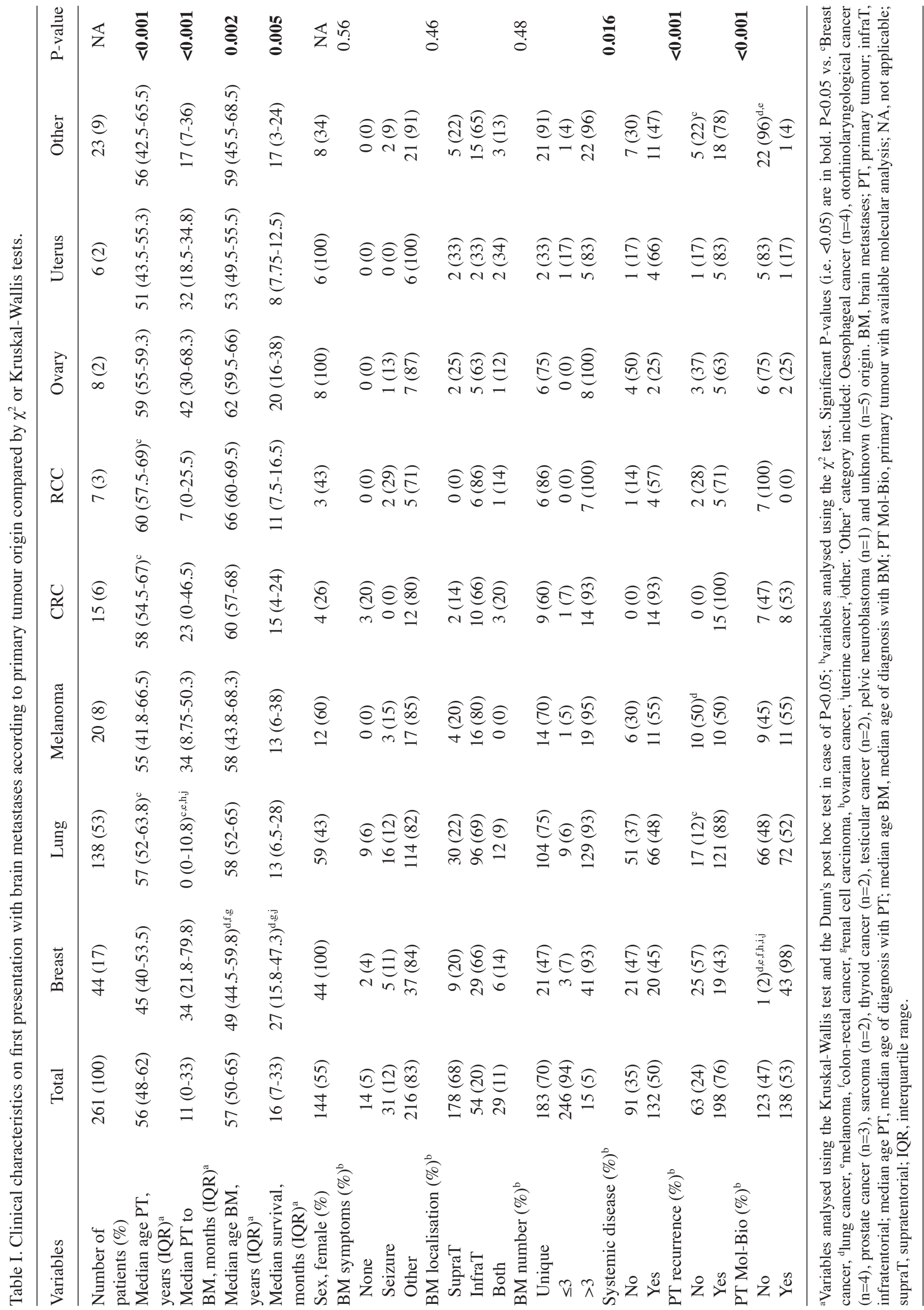


Table II. Clinical characteristics on first presentation with brain metastases according to brain metastasis type compared by $\chi^{2}$, Fisher's exact or Kruskal-Wallis tests.

\begin{tabular}{|c|c|c|c|c|}
\hline Parameters & dPT group & pPT group & uPT group & P-value \\
\hline Number of patients (\%) & $24(10)$ & $139(53)$ & $98(37)$ & NA \\
\hline Median age PT, years (IQR) ${ }^{\mathrm{a}}$ & $53(43.8-59.3)$ & $56(45.5-61.5)$ & $57(52-65)^{d}$ & 0.03 \\
\hline Median PT to BM, months (IQR) ${ }^{\mathrm{a}}$ & $41.5(35.8-85.5)^{\mathrm{e}, \mathrm{f}}$ & $22(11-44.5)^{\mathrm{f}}$ & $0(0)$ & $<0.001$ \\
\hline Median age BM, years (IQR) ${ }^{\mathrm{a}}$ & $57(48-64.8)$ & $58(48-66)$ & $57(52-65)$ & 0.9 \\
\hline PT Mol-Bio $(\%)^{\mathrm{c}}$ & & & & $<0.01$ \\
\hline No & $4(17)^{\mathrm{e}, \mathrm{f}}$ & $72(51)$ & $47(48)$ & \\
\hline Yes & $20(83)$ & $67(48)$ & $51(52)$ & \\
\hline Sex, female $(\%)^{\mathrm{b}}$ & $20(83)^{\mathrm{e}}$ & $82(59)$ & $41(42)^{\mathrm{d}, \mathrm{e}}$ & $<0.001$ \\
\hline BM symptoms $(\%)^{\mathrm{c}}$ & & & & 0.01 \\
\hline None & $2(8)$ & $12(9)$ & $0(0)^{\mathrm{d}, \mathrm{e}}$ & \\
\hline Seizure & $6(25)^{\mathrm{e}}$ & $12(9)$ & $13(13)$ & \\
\hline Other & $16(67)$ & $115(82)$ & $85(86)$ & \\
\hline BM localization $(\%)^{\mathrm{c}}$ & & & & 0.49 \\
\hline InfraT & $5(20)$ & $28(20)$ & $21(21)$ & \\
\hline SupraT & $19(79)$ & $94(68)$ & $66(67)$ & \\
\hline Both & $0(0)$ & $17(12)$ & $11(11)$ & \\
\hline $\mathrm{BM}$ number $^{\mathrm{c}}$ & & & & 0.9 \\
\hline Unique (\%) & $18(75)$ & $96(69)$ & $69(70)$ & \\
\hline$\leq 3(\%)$ & $4(16)$ & $34(24)$ & $24(24)$ & \\
\hline$>3(\%)$ & $2(8)$ & $9(6)$ & $5(5)$ & \\
\hline Tot $(\mathrm{IQR})^{\mathrm{a}}$ & $1(1-4)$ & $1(1-8)$ & $1(1-13)$ & 0.92 \\
\hline Systemic disease $(\%)^{c}$ & & & & $<0.001$ \\
\hline No & $24(100)$ & $36(32)$ & $31(34)$ & \\
\hline Yes & $0(0)$ & $74(67)$ & $58(66)$ & \\
\hline PT recurrence $(\%)^{\mathrm{c}}$ & & & & $<0.001$ \\
\hline No & $24(100)$ & $39(28)$ & $0(0)$ & \\
\hline Yes & $0(0)$ & $100(72)$ & $98(100)$ & \\
\hline \multicolumn{5}{|l|}{ PT localisation (\%) } \\
\hline Other ${ }^{c}$ & $0(0)$ & $19(14)^{\mathrm{f}}$ & $4(4)$ & 0.01 \\
\hline Lung $^{\mathrm{c}}$ & $6(25)$ & $49(35)$ & $83(85)^{\mathrm{d}, \mathrm{e}}$ & $<0.01$ \\
\hline Mutations $^{c}$ & $2(50)$ & $13(65)$ & $21(43)$ & 0.27 \\
\hline Histological subtypes ${ }^{c}$ & & & & 0.73 \\
\hline Sclc & $1(16)$ & $5(10)$ & $10(12)$ & \\
\hline Adenok & $4(67)$ & $33(67)$ & $60(72)$ & \\
\hline Squamous & $1(16)$ & 7 (14) & $8(9)$ & \\
\hline $\mathrm{CRC}^{\mathrm{c}}$ & $0(0)$ & $12(8)$ & $3(3)$ & 0.08 \\
\hline $\mathrm{RCC}^{\mathrm{c}}$ & $0(0)$ & $4(3)$ & $3(3)$ & 0.69 \\
\hline Uterus $^{c}$ & $1(4)$ & $4(3)$ & $1(1)$ & 0.52 \\
\hline Breast $^{c}$ & $13(54)^{\mathrm{e}}$ & $31(22)$ & $0(0)$ & $<0.01$ \\
\hline Molecular subtypes ${ }^{c}$ & & & & 0.88 \\
\hline 3neg & $5(38)$ & $10(34)$ & NA & \\
\hline $\mathrm{HR}+/ \mathrm{HER} 2+$ & $2(15)$ & $5(17)$ & NA & \\
\hline HR-/HER2+ & $2(15)$ & $5(17)$ & NA & \\
\hline HR+/HER2- & $3(23)$ & $1(3)$ & NA & \\
\hline Melanoma $^{\mathrm{c}}$ & $2(8)$ & $14(10)$ & $4(4)$ & 0.23 \\
\hline Ovary $^{c}$ & $2(8)$ & $6(4)$ & $0(0)$ & 0.048 \\
\hline $\mathrm{BM}$ treatment $(\%)^{\mathrm{c}}$ & & & & 0.92 \\
\hline Surgery & $0(0)$ & $4(3)$ & $2(2)$ & \\
\hline Rtp & $2(8)$ & $7(5)$ & $1(1)$ & \\
\hline Surgery+Rtp & $22(92)$ & $128(92)$ & $90(92)$ & \\
\hline
\end{tabular}


Table II. Continued.

\begin{tabular}{lcccc}
\hline Parameters & dPT group & pPT group & uPT group & P-value \\
\hline Median survival, months (IQR) & 27.5(15.3-45.5) & $19(7-35)$ & $11(6-17)^{\mathrm{d}, \mathrm{e}}$ & $<\mathbf{0 . 0 0 1}$ \\
\hline
\end{tabular}

${ }^{\mathrm{a}}$ Variables analysed using the Kruskal-Wallis test and the Dunn's post hoc test in case of $\mathrm{P}<0.05$; ${ }^{\mathrm{b}}$ variables analysed using the $\chi^{2}$ test; ${ }^{\mathrm{c}} \mathrm{variables}$ analysed using the Fisher's exact test. Significant P-values (i.e. $<0.05$ ) are bold. P<0.05 vs. ${ }^{\mathrm{d}} \mathrm{dPT}$, ${ }_{\mathrm{e} P T} \mathrm{P}$, ${ }_{\mathrm{f}}^{\mathrm{uPT}}$. BM, brain metastases; PT, primary tumour; dPT group, group of patients experiencing a progression-free period following PT treatment without local or distant recurrence at the moment of BM diagnosis; uPT group, group of patients presenting with BMs from an unknown PT; pPT group, group of patients presenting with a BM from a known cancer with local or systemic progression, or both; median age PT, median age of diagnosis with PT; median age BM, median age of diagnosis with BM; PT Mol-Bio, primary tumour with available molecular analysis; adenoc., adenocarcinoma; CRC, colon-rectal cancer; ER, oestrogen receptors positive breast cancers; HER2, human epidermal growth factor receptor 2 protein positive breast cancers; HR, hormone receptors; infraT, infratentorial; NA, not applicable; 'Other' category included: Oesophageal cancer ( $\mathrm{n}=4)$, otorhinolaryngological cancer $(n=4)$, prostate cancer $(n=3)$, sarcoma $(n=2)$, thyroid cancer $(n=2)$, testicular cancer $(n=2)$, pelvic neuroblastoma $(n=1)$ and unknown ( $\mathrm{n}=5$ ) origin. PR, progesterone receptors positive breast cancers; RCC, renal cell carcinoma; Rtp, radiotherapy; sclc, small cells lung cancer; supraT, supratentorial; mutations, ALK/ROS-a/KRAS/EGFR positive non-small cells lung cancers; IQR, interquartile range.

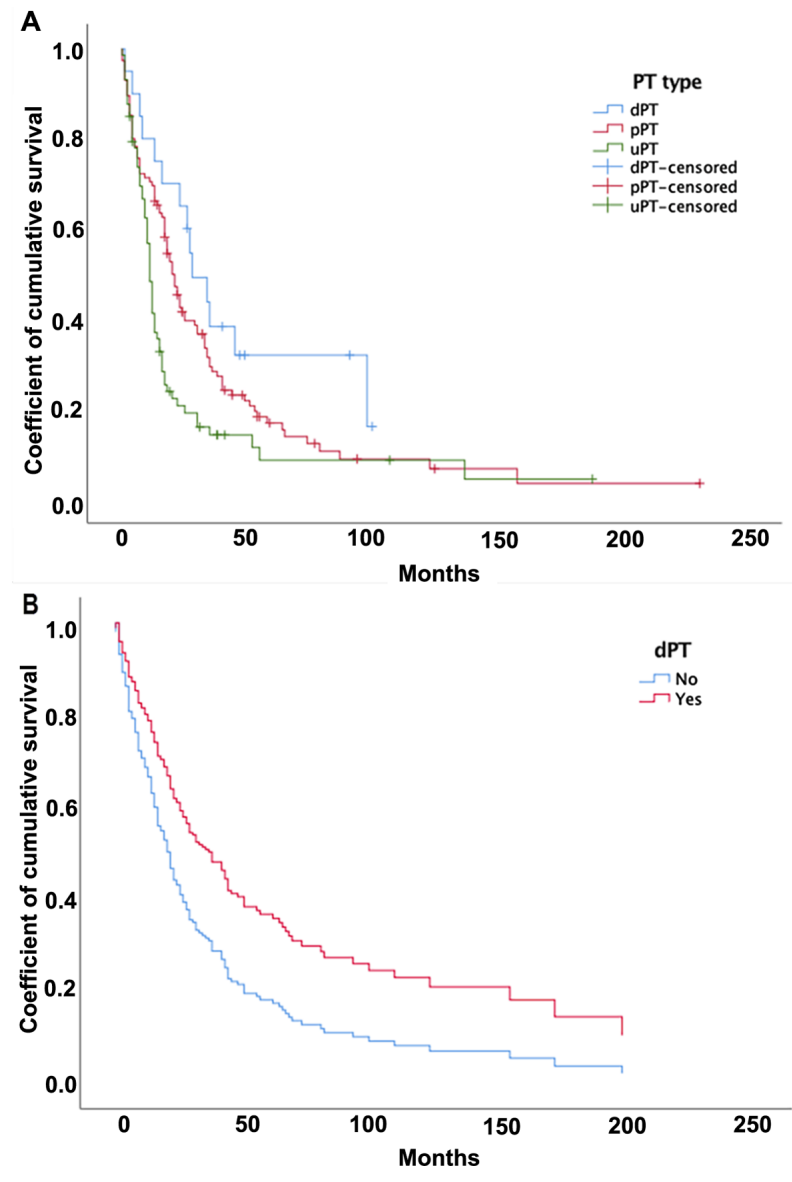

Figure 3. (A) Kaplan-Meier curves demonstrating the overall survival rate in the dPT group, as compared with that in the pPT (log-rank test; $\mathrm{P}=0.12$ ) and $\mathrm{uPT}(\mathrm{P}=0.006)$ groups. (B) Graph of Cox regression curve showing the overall survival rate of the $\mathrm{dPT}$ group, as compared with that of the no dPT group (i.e. pPT and uPT groups), after correcting for age, presence of breast cancer and treatment for the metastases. A trend towards a better outcome was evident in the dPT group, although it was not statistically significant $(\mathrm{P}=0.057)$.

$14(5 \%)$ BMs were asymptomatic and were detected during a follow-up brain imaging. A total of $178(68 \%)$ BMs were supratentorial, and $183(70 \%)$ were unique. In $209(80 \%)$ cases, a systemic active disease was observed, which was a metastatic localization beyond the $\mathrm{BM}$ and/or a $\mathrm{PT}$ recurrence at the first presentation of BM. In 123 (47\%) cases, molecular analysis was not available.

Patient characteristics divided according to BM type are summarized in Table II. A total of $24(10 \%)$ patients fulfilled the inclusion criteria for the dPT, 139 (53\%) for the pPT and $98(37 \%)$ for the uPT groups. Regarding BM localization and the number of metastases, the groups did not present any statistically significant differences. In the univariate analysis, patients with dPT were younger [53 (IQR, 43.8-59.30 years old) vs. 57 (IQR, 52-65) in the uPT group; $\mathrm{P}<0.033)$ ] when the PT was diagnosed, but due to the longer time elapsed until the $\mathrm{BM}$ diagnosis, the groups did not differ in terms of age at $\mathrm{BM}$ diagnosis $(\mathrm{P}=0.9)$. The $\mathrm{dPT}$ patients were more frequently female [ 83 vs. $59(\mathrm{P}=0.03)$ and $42 \%(\mathrm{P}<0.001)$ in the pPT and uPT groups, respectively]. In up to $25 \%$ of patients in the dPT group, the clinical presentation of BM was predominantly seizures, with a frequency 2 times higher than that in other patients. A statistically significant difference in PT origin was observed; breast cancer was the most common PT origin in the dPT group ( $n=13 ; 54 \%)$, whereas lung cancer was the most common in the uPT group $(n=83 ; 85 \%)$. No differences were reported between the histological and molecular subgroups for either breast or lung cancer. The rate of PT recurrence and presence of an active systemic disease differed between groups $(\mathrm{P}<0.01)$. Of note, by definition, patients in the dPT group did not present PT recurrence or other metastatic localizations. Thorough evaluations (e.g. full-body CT and PET scans) did not show any metastatic localizations, other than those in the brain, in $\sim 1 / 3$ of patients from either the pPT or uPT group $(n=36$ and $\mathrm{n}=31$, respectively). The PT recurred in $100(72 \%)$ patients in the pPT group. The rate of molecular biology analysis was higher in the dPT group than in the other groups $(\mathrm{P}<0.01)$.

Survival analysis. Follow-up data were available for 208 patients ( $79 \%$ of the entire sample); $17 \%$ of patients $(n=35)$ were still alive at the time of the final analysis. The results of the survival analysis are summarized in Tables III and SI. In the univariate model, a longer time between $\mathrm{PT}$ and $\mathrm{BM}$ diagnoses $(\mathrm{P}=0.021)$, female sex $(\mathrm{P}<0.001)$, breast cancer $(\mathrm{P}=0.02)$, presence of molecular biology analysis $(\mathrm{P}=0.007)$ and treatment with 
Table III. Univariate and multivariate Cox regression for survival analysis.

\begin{tabular}{|c|c|c|c|c|c|c|c|c|}
\hline \multirow[b]{2}{*}{ Parameters } & \multicolumn{2}{|c|}{ Overall survival (months) } & \multicolumn{3}{|c|}{ Univariate $\mathrm{COX}$ regression } & \multicolumn{3}{|c|}{ Multivariate Cox regression } \\
\hline & median & {$[95 \% \mathrm{CI}]$} & HR & {$[95 \% \mathrm{CI}]$} & P-value & $\mathrm{HR}$ & {$[95 \% \mathrm{CI}]$} & P-value \\
\hline \multicolumn{9}{|l|}{ Sex } \\
\hline $\mathrm{F}$ & 21 & [18.9-27] & 0.52 & [0.38-0.72] & $<0.001$ & NA & NA & NA \\
\hline $\mathrm{M}^{\mathrm{a}}$ & 13 & [10.9-15.1] & & & & & & \\
\hline \multicolumn{9}{|l|}{ BM symptoms } \\
\hline None & 24 & {$[5.2-42.8]$} & 0.73 & [0.39-1.35] & 0.32 & NA & NA & NA \\
\hline Seizure & 18 & {$[12.2-23.7]$} & 0.84 & {$[0.51-1.37]$} & 0.49 & NA & NA & NA \\
\hline Other $^{\mathrm{a}}$ & 16 & [12.6-19.4] & & & & & & \\
\hline \multicolumn{9}{|l|}{ BM localisation } \\
\hline InfraT & 17 & {$[3.4-30.6]$} & 0.58 & {$[0.33-1.02]$} & 0.23 & NA & NA & NA \\
\hline SupraT & 17 & {$[13.7-20.3]$} & 0.69 & {$[0.43-1.11]$} & 0.99 & NA & NA & NA \\
\hline Both $^{\mathrm{a}}$ & 13 & {$[9.5-16.5]$} & & & & & & \\
\hline \multicolumn{9}{|l|}{ BM number } \\
\hline Unique $^{\mathrm{a}}$ & 17 & [13.5-20.5] & & & & & & \\
\hline$\leq 3$ & 17 & {$[11.5-22.5]$} & 0.98 & {$[0.68-1.41]$} & 0.92 & NA & NA & NA \\
\hline$>3$ & 19 & {$[11.7-26.3]$} & 0.78 & {$[0.42-1.45]$} & 0.43 & NA & NA & NA \\
\hline \multicolumn{9}{|l|}{ PT recurrence } \\
\hline No & 30 & [21.3-38.7] & 0.52 & {$[0.36-0.74]$} & $<0.001$ & NA & NA & NA \\
\hline $\mathrm{Yes}^{\mathrm{a}}$ & 14 & [11-16.9] & & & & & & \\
\hline \multicolumn{9}{|l|}{ PT Mol-Bio } \\
\hline $\mathrm{No}^{\mathrm{a}}$ & 13 & [10.1-15.9] & & & & & & \\
\hline Yes & 20 & [12.6-27.4] & 0.66 & [0.49-0.89] & 0.007 & NA & NA & NA \\
\hline \multicolumn{9}{|l|}{ Systemic disease } \\
\hline No & 20 & [11.9-28.1] & 0.62 & {$[0.45-0.87]$} & 0.008 & NA & NA & NA \\
\hline Yes $^{\mathrm{a}}$ & 13 & [9.9-16.1] & & & & & & \\
\hline Age BM & NA & NA & 1.02 & [1.01-1.03] & 0.009 & 1.016 & [1.003-1.03] & 0.016 \\
\hline \multicolumn{9}{|l|}{$\mathrm{BM}$ treatment } \\
\hline Surgery + Rtp & 17 & [13.9-20.1] & 0.5 & {$[0.28-0.88]$} & 0.03 & 0.538 & {$[0.31-0.95]$} & 0.034 \\
\hline Rtp or surgery ${ }^{a}$ & 8 & [2.7-13.3] & & & & & & \\
\hline \multicolumn{9}{|l|}{ PT localization } \\
\hline Breast & 34 & [24.1-43.9] & 0.64 & [0.41-0.99] & 0.02 & 0.75 & {$[0.50-1.13]$} & 0.172 \\
\hline Lung & 14 & [10.7-17.3] & 1.02 & [0.72-1.143] & 0.16 & NA & NA & NA \\
\hline Other $^{\mathrm{a}}$ & 17 & [11.4-22.6] & & & & & & \\
\hline \multicolumn{9}{|l|}{$\mathrm{dPT}$} \\
\hline Yes & 28 & [17-1-38.9] & 0.58 & [0.33-0.99] & 0.048 & 0.59 & [0.34-1.02] & 0.057 \\
\hline $\mathrm{No}^{\mathrm{a}}$ & 16 & [13.3-18.7] & & [17-1-38.9] & & & & \\
\hline
\end{tabular}

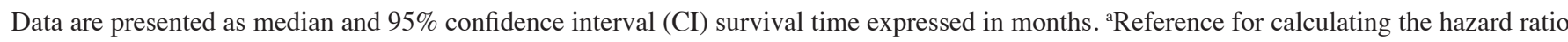
in the univariate analysis. BM, brain metastases; PT, primary tumour; dPT, patients experiencing a progression-free period following PT treatment without local or distant recurrence at the moment of BM diagnosis; infraT, infratentorial; PT Mol-Bio, primary tumour with available molecular analysis; NA, not applicable; Rtp, radiotherapy; supraT, supratentorial. Multivariate Cox regression significant P-values (i.e. $<0.05$ ) are bold.

neurosurgery and radiotherapy $(\mathrm{P}=0.03)$ were associated with a better outcome. By contrast, the presence of systemic disease $(\mathrm{P}=0.008)$, PT recurrence $(\mathrm{P}<0.001)$ and older age $(\mathrm{P}=0.009)$ were factors that negatively influenced prognosis.

The Kaplan-Meier curves (Fig. 3) showed that patients in the dPT group had a significantly longer survival than patients in the uPT group [28 (IQR 15.3-45.5) vs. 11 (IQR 6-17) months; $\mathrm{P}=0.005]$, but no difference was observed compared to patients in the pPT group [19 (IQR 6-17) months; $\mathrm{P}=0.12$ )]. Multivariate Cox analysis (Table III) showed that survival was statistically correlated with a younger age at BM diagnosis, with a $2 \%$ increase in the risk of mortality per year [hazard 
ratio (HR), 1.02; $\mathrm{P}=0.016]$, as well as with neurosurgery and radiotherapy treatment, which reduced the risk of mortality by $\sim 50 \%$, as compared to surgery or radiotherapy alone (HR, $0.53 ; \mathrm{P}=0.034$ ). The dPT group had a longer survival than the other groups (Fig. 3), with a $41 \%$ reduction in mortality (HR, 0.59; $\mathrm{P}=0.057)$. The model failed to show improved survival for patients with breast cancer as the PT.

\section{Discussion}

To the best of our knowledge, this was the first study focusing specifically on the clinical characteristics and survival of patients presenting with dormant BMs (dPT group). In particular, in the multivariate analysis, $\mathrm{dPT}$ patients exhibited a tendency, albeit not significant $(\mathrm{P}=0.057)$, towards an improved outcome; $\mathrm{dPT}$ patients presented a median survival of 28 months and a 5-year survival rate of $14 \%$ (vs. 16 months and 5\%, respectively, in the non-dormant group). Since there is no clinical definition of dormant BM, the arbitrary threshold of 30 months of progression-free disease before BM diagnosis was used, which was derived from mathematical models developed for breast cancer (28). Moreover, by excluding patients with systemic disease or PT recurrence, the probability of including BMs derived from a PT or other metastatic localizations was reduced. Thus, even if the present study could not exclude that BMs growing from dormant DTCs could be present in groups other than the dPT group, the authors are confident that the current dormant population was appropriately selected. On the other hand, this overlap might have influenced the statistical significance of the inter-group comparisons. Whether some specific characteristics of dormant metastasis affect survival remains unknown.

Solitary tumour cell dormancy is defined as a reversible non-proliferative cellular state characterized by temporary mitotic and growth arrest (13), probably due to a delayed DTCs adaptation to the microenvironment of the pre-metastatic site (14). The mechanism responsible for 'awakening' DTC dormant cells to an actively proliferating phenotype has not been completely elucidated, but has been found to be dependent on the balance between intrinsic and microenvironmental factors (29). Following the occurrence of genetic or epigenetic mutations, such as the activation of growth factor signalling (30) and expression of pro-angiogenetic molecules (31), which is a required step for proliferation (15-19), the dormant DTCs are reactivated; however, they only grow into metastasis in the presence of a permissive microenvironment. In addition to extracellular matrix components or soluble ligands able to arrest proliferation (32), brain-resident cells, such as microglia and astrocytes, provide an environment that affects the development of metastatic brain tumours. Early contact between DTCs and astrocytes might lead to tumour cell death (33). However, there is accumulating evidence that astrogliosis can provide support for tumour outgrowth (34), and activated astrocytes can affect microglia and $\mathrm{T}$ cell functions, creating an immunosuppressive microenvironment that promotes DTC proliferation (35). Furthermore, circulating immune cells could put additional survival pressure on cancer cells arrested within the cerebral capillaries prior to extravasation (36). It could be speculated that patients who have a more efficient immune system and exhibit a preferential differentiation of brain-resident cells towards a neuroprotective phenotype can more effectively control BM growth. On the other hand, it has been demonstrated that the biology of DTCs diverges from that of the PT or overt metastases (23); furthermore, studies have shown that, in certain types of cancer, dissemination occurs in the early phase or even before the PT is detectable (9). BMs growing from previously dormant DTCs might present a milder phenotype (37) than those derived from progressing, and thus more aggressive, PT tumours, which partially explains the longer survival of patients with dormant metastasis. Although certain studies have already identified the dormancy-related genetic profiles in the PT associated with the occurrence of delayed metastasis $(15,38)$, the most clinically useful analyses would focus on dormant DTC profiling (39). This approach might provide targets to aid the development of drugs that can induce or maintain dormancy; furthermore, follow-ups of the most frequent DTC-hosting organs, such as a yearly evaluation of the bone marrow in patients with breast cancer, may allow for the detection of markers of awakening DTCs, which would necessitate therapeutic escalation (39).

With regard to BM characteristics, seizures at BM diagnosis were more frequent in patients with dormant BM, which could be partially due to the preponderant, albeit not significant, supratentorial localisation of dormant BMs. Although BMs from melanoma have been described as more likely to lead to seizures, due to their haemorrhagic and cortical predilection (40), PT localisation did not influence BM clinical presentation. Age negatively influenced survival in the present sample, which was consistent with previous studies $(2,41)$; as a consequence, despite the lack of statistical significance, the younger age of the dPT patients is likely to have positively influenced their outcome. Of note, no prognostic advantage of BMs originating from breast cancer was observed over BMs with different PT origins $(1,2,42)$. Since the most prevalent PT origin in the dPT group was the breast, the fact that this location did not influence survival reinforced the prognostic role of dormant BM. No differences were observed in the histological subtypes of primary cancer types $(43,44)$, probably since the majority of the patients included in the present study had undergone surgery, minimizing the effect of BM from PT with a different radiosensitivity on survival.

Molecular biology analysis of the PT was more often available for dPT patients, and this was statistically correlated with survival in the univariate Cox model. Despite the lack of complete information on the medical treatment of these patients, the use of molecular-targeted therapy, such as trastuzumab for human epidermal growth factor receptor 2-positive breast cancers (26), dabrafenib plus trametinib for v-raf murine sarcoma viral oncogene homolog $\mathrm{B} 1^{\mathrm{V} 600}$-mutant melanoma (45), brigatinib for anaplastic lymphoma kinase-positive non-small-cell lung cancer (46) or gifetinib for epidermal growth factor receptor-positive non-small-cell lung cancer metastases (47), which has been shown to exert beneficial survival effects, might partially explain this finding. As expected $(48,49)$, the best available treatment (the combination of neurosurgery and radiotherapy) in selected patients, was a strong predictive factor of favourable prognosis.

The present study had several limitations. Since only patients considered for neurosurgery or brain biopsy were included in the study, a major source of bias in the survival analysis could not be avoided. In fact, patients who undergo 
surgery usually have a more favourable prognosis, since the selection process for this population included criteria that positively influence survival, such as the Karnofsky performance status (KPS), the number of metastases and the presence of a controlled systemic disease (50). Although overall survival might have been overestimated, this did not affect the statistical analysis, since all groups only included patients who had undergone surgery. As there is no clinical definition of dormant BM, the current study's definition of it as a delay of 30 months between PT and BM diagnosis was questionable. In particular, despite the fact that dormant DTCs are supposed to be chemo-resistant $(11,51)$, it could not be excluded that systemic chemotherapy could have influenced progression-free-survival by effectively limiting BM growth. Nevertheless, the same trend in survival resulted in the multivariate survival analysis of the dPT group including only patients presenting with a minimum of 30 months of progression-free disease under no systemic treatment (cf. Table SII). The limited number of patients did not allow for comparisons among all available parameters in the multivariate models; this was the reason why no multivariate model was built to compare differences between BM groups. In addition, previous studies showed that the absence of systemic disease, in the form of PT recurrence and/or metastatic localizations in organs other than the brain, were favourable prognostic factors for the BM population $(41,52)$. Since these variables were not tested in the multivariate model, it could not be excluded that they played a role in helping the dPT group achieve a longer survival. Due to the retrospective nature of the present study, the KPS score was not available in all patients. Since the KPS is a major prognostic factor (2), it could have influenced survival analysis. Although sex was correlated with outcome in long-surviving BM patients (53), we preferred to include PT origin (breast) in the multivariate Cox regression model, since these two factors were highly correlated.

In conclusion, the results of the present study showed that BM growing from previously dormant DTCs tends to be associated with a better outcome than other types of BMs, possibly due to the less aggressive phenotype of these BMs. This information could be included in prognostication models. Moreover, the development of therapies able to eradicate dormant DTCs could comprise a new promising strategy to prolong survival (13).

\section{Acknowledgements}

The authors would like to express their appreciation to Dr Dormal Giulia (Saint Luc Hospital, Catholic University of Leuven, Belgium) and Mr. Biondi Filippo (Catholic University of Leuven, Belgium) for their help in the statistical analysis of this work.

\section{Funding}

No funding was received.

\section{Availability of data and materials}

The datasets used and/or analysed during the current study are available from the corresponding author on reasonable request.

\section{Authors' contributions}

FL conceived the original idea. LF, VL and LP collected the data, performed the statistical analysis with $\mathrm{NG}$, and they all interpretated the data. LF wrote the manuscript, which was critically revised by FL and NG. FL and LF confirm the authenticity of all the raw data. All authors discussed the results, commented on the manuscript and approved the final version to be published. All authors read and approved the final manuscript.

\section{Ethics approval and consent to participate}

The ethics committee of the Erasmus Hospital (Free University of Bruxelles, Brussels, Belgium) approved the protocol (reference P2019/319).

\section{Patient consent for publication}

It was impossible to obtain permission for publication from patients reported in the CASE boxes since the patients are deceased and no further contact was possible with any next of kin. Moreover, after verification in our institution archives, none of the patients ever expressed any objection to anonymous publication of personal data. For these reasons, the present study was granted an exemption from requiring patient consent for publication. This decision was in accordance with the ethics committee of the Erasmus Hospital (Free University of Bruxelles, Brussels, Belgium).

\section{Competing interests}

The authors declare that they have no competing interests.

\section{References}

1. Achrol AS, Rennert RC, Anders C, Soffietti R, Ahluwalia MS, Nayak L, Peters S, Arvold ND, Harsh GR, Steeg PS and Chang SD: Brain metastases. Nat Rev Dis Primer 5: 5, 2019.

2. Sperduto PW, Kased N, Roberge D, Xu Z, Shanley R, Luo X, Sneed PK, Chao ST, Weil RJ, Suh J, et al: Summary report on the graded prognostic assessment: An accurate and facile diagnosis-specific tool to estimate survival for patients with brain metastases. J Clin Oncol 30: 419-425, 2012.

3. Lowery FJ and Yu D: Brain metastasis: Unique challenges and open opportunities. Biochim Biophys Acta Rev Cancer 1867: 49-57, 2017

4. Tsukada Y, Fouad A, Pickren JW and Lane WW: Central nervous system metastasis from breast carcinoma. Autopsy study. Cancer 52: 2349-2354, 1983

5. Nayak L, Lee EQ and Wen PY: Epidemiology of brain metastases. Curr Oncol Rep 14: 48-54, 2012.

6. Tabouret E, Chinot O, Metellus P, Tallet A, Viens P and Gonçalves A: Recent trends in epidemiology of brain metastases: An overview. Anticancer Res 32: 4655-4662, 2012.

7. Schardt JA, Meyer M, Hartmann CH, Schubert F, Schmidt-Kittler O, Fuhrmann C, Polzer B, Petronio M, Eils R and Klein CA: Genomic analysis of single cytokeratin-positive cells from bone marrow reveals early mutational events in breast cancer. Cancer Cell 8: 227-239, 2005.

8. Hüsemann Y, Geigl JB, Schubert F, Musiani P, Meyer M, Burghart E, Forni G, Eils R, Fehm T, Riethmüller G and Klein CA: Systemic spread is an early step in breast cancer. Cancer Cell 13: 58-68, 2008.

9. Harper KL, Sosa MS, Entenberg D, Hosseini H, Cheung JF, Nobre R, Avivar-Valderas A, Nagi C, Girnius N, Davis RJ, et al: Mechanism of early dissemination and metastasis in Her2 ${ }^{+}$ mammary cancer. Nature 540: 588-592, 2016. 
10. Rhim AD, Mirek ET, Aiello NM, Maitra A, Bailey JM, McAllister F, Reichert M, Beatty GL, Rustgi AK, Vonderheide RH, et al: EMT and dissemination precede pancreatic tumor formation. Cell 148: 349-361, 2012.

11. Aguirre-Ghiso JA: Models, mechanisms and clinical evidence for cancer dormancy. Nat Rev Cancer 7: 834-846, 2007.

12. Goss PE and Chambers AF: Does tumour dormancy offer a therapeutic target? Nat Rev Cancer 10: 871-877, 2010.

13. Sosa MS, Bragado P and Aguirre-Ghiso JA: Mechanisms of disseminated cancer cell dormancy: An awakening field. Nat Rev Cancer 14: 611-622, 2014.

14. Giancotti FG: Mechanisms governing metastatic dormancy and reactivation. Cell 155: 750-764, 2013.

15. Gao H, Chakraborty G, Lee-Lim AP, Mo Q, Decker M, Vonica A, Shen R, Brogi E, Brivanlou AH and Giancotti FG: The BMP inhibitor coco reactivates breast cancer cells at lung metastatic sites. Cell 150: 764-779, 2012.

16. O'Connell JT, Sugimoto H, Cooke VG, MacDonald BA, Mehta AI, LeBleu VS, Dewar R, Rocha RM, Brentani RR, Resnick MB, et al: VEGF-A and Tenascin-C produced by S100A4+ stromal cells are important for metastatic colonization. Proc Natl Acad Sci USA 108: 16002-16007, 2011.

17. Gao D, Nolan DJ, Mellick AS, Bambino K, McDonnell K and Mittal V: Endothelial progenitor cells control the angiogenic switch in mouse lung metastasis. Science 319: 195-198, 2008

18. Aguirre-Ghiso JA, Ossowski L and Rosenbaum SK: Green fluorescent protein tagging of extracellular signal-regulated kinase and p38 pathways reveals novel dynamics of pathway activation during primary and metastatic growth. Cancer Res 64 7336-7345, 2004.

19. Tsai JH, Donaher JL, Murphy DA, Chau S and Yang J: Spatiotemporal regulation of epithelial-mesenchymal transition is essential for squamous cell carcinoma metastasis. Cancer Cell 22: 725-736, 2012.

20. Liu Q, Zhang H, Jiang X, Qian C, Liu Z and Luo D: Factors involved in cancer metastasis: A better understanding to 'seed and soil' hypothesis. Mol Cancer 16: 176, 2017.

21. Demicheli R, Biganzoli E, Boracchi P, Greco M and Retsky MW: Recurrence dynamics does not depend on the recurrence site. Breast Cancer Res 10: R83, 2008.

22. Retsky MW, Demicheli R, Swartzendruber DE, Bame PD, Wardwell RH, Bonadonna G, Speer JF and Valagussa P: Computer simulation of a breast cancer metastasis model. Breast Cancer Res Treat 45: 193-202, 1997.

23. Klein CA: Selection and adaptation during metastatic cancer progression. Nature 501: 365-372, 2013.

24. Bilous M, Serdjebi C, Boyer A, Tomasini P, Pouypoudat C, Barbolosi D, Barlesi F, Chomy F and Benzekry S: Quantitative mathematical modeling of clinical brain metastasis dynamics in non-small cell lung cancer. Sci Rep 9: 13018, 2019.

25. Sun YW, Xu J, Zhou J and Liu WJ: Targeted drugs for systemic therapy of lung cancer with brain metastases. Oncotarget 9 : $5459-5472,2017$

26. Leyland-Jones B: Human epidermal growth factor receptor 2 -positive breast cancer and central nervous system metastases. J Clin Oncol 27: 5278-5286, 2009.

27. Piura E and Piura B: Brain Metastases from Ovarian Carcinoma ISRN Oncol : 527453, 2011

28. Demicheli R, Retsky MW, Hrushesky WJ and Baum M: Tumor dormancy and surgery-driven interruption of dormancy in breast cancer: Learning from failures. Nat Clin Pract Oncol 4: 699-710, 2007.

29. Neophy tou CM, Kyriakou TC and Papageorgis P: Mechanisms of metastatic tumor dormancy and implications for cancer therapy. Int J Mol Sci 20: 6158, 2019.

30. Aguirre-Ghiso JA, Liu D, Mignatti A, Kovalski K and Ossowski L: Urokinase receptor and fibronectin regulate the ERK(MAPK) to p38(MAPK) activity ratios that determine carcinoma cell proliferation or dormancy in vivo. Mol Biol Cell 12: 863-879, 2001

31. Yeh AC and Ramaswamy S: Mechanisms of cancer cell dormancy-another hallmark of cancer? Cancer Res 75: 5014-5022, 2015

32. Ghajar CM, Peinado H, Mori H, Matei IR, Evason KJ, Brazier H, Almeida D, Koller A, Hajjar KA, Stainier DY, et al: The perivascular niche regulates breast tumour dormancy. Nat Cell Biol 15: 807-817, 2013

33. Valiente M, Obenauf AC, Jin X, Chen Q, Zhang XHF, Lee DJ, Chaft JE, Kris MG, Huse JT, Brogi E and Massagué J: Serpins promote cancer cell survival and vascular co-option in brain metastasis. Cell 156: 1002-1016, 2014
34. Schulz M, Salamero-Boix A, Niesel K, Alekseeva T and Sevenich L: Microenvironmental regulation of tumor progression and therapeutic response in brain metastasis. Front Immunol 10: 1713, 2019.

35. Priego N, Zhu L, Monteiro C, Mulders M, Wasilewski D, Bindeman W, Doglio L, Martínez L, Martínez-Saez E, Ramón Y, et al: STAT3 labels a subpopulation of reactive astrocytes required for brain metastasis. Nat Med 24: 1024-1035, 2018

36. Lorger M and Felding-Habermann B: Capturing changes in the brain microenvironment during initial steps of breast cancer brain metastasis. Am J Pathol 176: 2958-2971, 2010.

37. Schmidt-Kittler O, Ragg T, Daskalakis A, Granzow M, Ahr A, Blankenstein TJF, Kaufmann M, Diebold J, Arnholdt H, Muller P, et al: From latent disseminated cells to overt metastasis: Genetic analysis of systemic breast cancer progression. Proc Nat Acad Sci USA 100: 7737-7742, 2003.

38. Kobayashi A, Okuda H, Xing F, Pandey PR, Watabe M, Hirota S, Pai SK, Liu W, Fukuda K, Chambers C, et al: Bone morphogenetic protein 7 in dormancy and metastasis of prostate cancer stem-like cells in bone. J Exp Med 208: 2641-2655, 2011.

39. Aguirre-Ghiso JA, Bragado P and Sosa MS: Metastasis awakening: Targeting dormant cancer. Nat Med 19: 276-277, 2013.

40. Noh T and Walbert T: Brain metastasis: Clinical manifestations, symptom management, and palliative care. Handb Clin Neurol 149: 75-88, 2018

41. D'Ambrosio AL and Agazzi S: Prognosis in patients presenting with brain metastasis from an undiagnosed primary tumor. Neurosurg Focus 22: E7, 2007.

42. Rostami R, Mittal S, Rostami P, Tavassoli F and Jabbari B: Brain metastasis in breast cancer: A comprehensive literature review. J Neurooncol 127: 407-414, 2016.

43. Kuremsky JG, Urbanic JJ, Petty WJ, Lovato JF, Bourland JD, Tatter SB, Ellis TL, McMullen KP, Shaw EG and Chan MD: Tumor histology predicts patterns of failure and survival in patients with brain metastases from lung cancer treated with gamma knife radiosurgery. Neurosurgery 73: 641-647, 2013.

44. Vern-Gross TZ, McMullen KP, Case LD, Bourland JD, Ellis TL, Lawrence JA, Tatter SB, Shaw EG, Urbanic JJ and Chan MD: Patterns of failure in patients receiving gamma knife radiosurgery for breast carcinoma to the brain. Int J Radiat Oncol 81 (Suppl): S216-S217, 2011.

45. Davies MA, Saiag P, Robert C, Grob JJ, Flaherty KT, Arance A, Chiarion-Sileni V, Thomas L, Lesimple T, Mortier L, et al: Dabrafenib plus trametinib in patients with BRAFV600-mutant melanoma brain metastases (COMBI-MB): A multicentre, multicohort, open-label, phase 2 trial. Lancet Oncol 18: 863-873, 2017

46. Kim DW, Tiseo M, Ahn MJ, Reckamp KL, Hansen KH, Kim SW, Huber RM, West HL, Groen HJM, Hochmair MJ, et al: Brigatinib in patients with crizotinib-refractory anaplastic lymphoma kinase-positive non-small-cell lung cancer: A randomized, multicenter phase II trial. J Clin Oncol 35: 2490-2498, 2017.

47. Iuchi T, Shingyoji M, Sakaida T, Hatano K, Nagano O, Itakura M, Kageyama H, Yokoi S, Hasegawa Y, Kawasaki K and Iizasa T: Phase II trial of gefitinib alone without radiation therapy for Japanese patients with brain metastases from EGFR-mutant lung adenocarcinoma. Lung Cancer 82: 282-287, 2013.

48. Patchell RA, Tibbs PA, Walsh JW, Dempsey RJ, Maruyama Y, Kryscio RJ, Markesbery WR, Macdonald JS and Young B: A randomized trial of surgery in the treatment of single metastases to the brain. N Engl J Med 322: 494-500, 1990.

49. Lin X and DeAngelis LM: Treatment of brain metastases. J Clin Oncol 33: 3475-3484, 2015.

50. Soffietti R, Abacioglu U, Baumert B, Combs SE, Kinhult S, Kros JM, Marosi C, Metellus P, Radbruch A, Freixa SSV, et al: Diagnosis and treatment of brain metastases from solid tumors: Guidelines from the european association of neuro-oncology (EANO). Neuro Oncol 19: 162-174, 2017.

51. Dean M, Fojo T and Bates S: Tumour stem cells and drug resistance. Nat Rev Cancer 5: 275-284, 2005.

52. Ekici K, Temelli O, Dikilitas M, Halil Dursun I, Bozdag Kaplan N and Kekilli E: Survival and prognostic factors in patients with brain metastasis: Single center experience. J BUON 21: 958-963, 2016.

53. Chao ST, Barnett GH, Liu SW, Reuther AM, Toms SA, Vogelbaum MA, Videtic GMM and Suh JH: Five-year survivors of brain metastases: A single-institution report of 32 patients. Int J Radiat Oncol Biol Phys 66: 801-809, 2006.

This work is licensed under a Creative Commons Attribution-NonCommercial-NoDerivatives 4.0 International (CC BY-NC-ND 4.0) License. 